\title{
Effect of Silica Fume and SBR Latex on the Paste-aggregate Interfacial Transition Zone
}

\author{
João Adriano Rossignolo* \\ Department of Architecture and Urbanism, Engineering School of São Carlos, \\ University of São Paulo, Av. Trabalhador Saocarlense 400, 13560-583 São Carlos - SP, Brazil
}

Received: November 20, 2006; Revised: January 30, 2007

\begin{abstract}
This paper deals with the effect of silica fume and styrene-butadiene latex (SBR) on the microstructure of the interfacial transition zone (ITZ) between Portland cement paste and aggregates (basalt). Scanning Electron Microscope (SEM) equipped with energy dispersive $\mathrm{x}$ ray analysis system (EDX) was used to determine the ITZ thickness. In the plain concrete a marked ITZ around the aggregate particles $(55 \mu \mathrm{m})$ was observed, while in concretes with silica fume or latex SBR the ITZ was less pronounced (35-40 $\mu \mathrm{m})$. However, better results were observed in concretes with silica fume and latex SBR $(20-25 \mu \mathrm{m})$.
\end{abstract}

Keywords: concrete, interfacial transition zone, silica fume, polymers, SEM

\section{Introduction}

Researches conducted since 2000 in the Civil Construction Laboratory of the Engineering School of São Carlos (University of São Paulo) have indicated that there is a great potential of the combined usage of silica fume and styrene-butadiene (SBR) latex in the increase in the performance of the concrete properties ${ }^{1-5}$.

To properly understand the effect of SBR latex and silica fume on concretes, this work presents an analysis of their effect on both thickness and structure of the ITZ between the aggregate and the cement matrix.

According to Monteiro ${ }^{6}$, before any systematic work is done to understand the cement matrix microstructure aiming to increase the concrete properties, studies which approach the improvement of the ITZ between the aggregate and the cement matrix should be prioritized, since many important properties of the concrete are significantly influenced by the characteristics of that ITZ.

Several researches present a strong relation between the thickness and the quality of the interfacial ITZ and some properties of the concretes, such as mechanical strength, elastic moduli, crack propagation mechanisms and permeability of aggressive agents in concretes, justifying the great importance of the study of the matrixaggregate ITZ ${ }^{6,7}$.

Some researches present results demonstrating that the mineral additions can produce a significant reduction in the thickness of the matrix-aggregate ITZ, besides the densification of such region, contributing to an improvement of the properties related to mechanical strength and concrete durability ${ }^{6-9}$.

Silica fume is considered a very effective mineral addition in the reduction of the thickness of the matrix-aggregate ITZ. In the results obtained by Monteiro and Mehta ${ }^{10,11}$, the reduction of the ITZ thickness from $50 \mu \mathrm{m}$, in concretes without mineral addition, to values below $10 \mu \mathrm{m}$, in concretes with silica fume, was verified.

In the concrete modified with SBR latex, it is possible to observe an improvement in the matrix-aggregate ITZ characteristics, such as reduction of both quantity of calcium hydroxide $(\mathrm{CH})$ and porosity, effects that can be attributed to the accumulation of polymer in this region. The ITZ between the aggregate and the cement matrix presents higher water quantity than the cement matrix, as a result of the wall effect, and consequently, higher polymer quantity, since in the modified concretes the polymer is dispersed in the liquid element. Therefore, the reduction in the $\mathrm{CH}$ quantity can be observed, due to the reactions of the carboxylic group of the copolymer particles with $\mathrm{Ca}^{2+}$ ions liberated during the cement hydration process thus reducing the $\mathrm{Ca}^{2+}$ quantity available for the $\mathrm{CH}$ formation ${ }^{12-14}$.

In that sense, this work presents an analysis of the effect the SBR latex and silica fume in the ITZ between the basaltic aggregate and the cement matrix. It was used a quantitative analysis by EDX (energy dispersive $\mathrm{x}$ ray analysis system) associated with SEM (Scanning Electron Microscope) for the analyses of the matrix-aggregate ITZ. The analyses were accomplished in the Civil Engineering National Laboratory in Lisbon (LNEC - Laboratório Nacional de Engenharia Civil), Portugal.

\section{Materials and Experimental Program}

In this experiment high-early-strength-Portland cement was used. Its density and Blaine fineness were $3120 \mathrm{~kg} / \mathrm{m}^{3}$ and $4680 \mathrm{~cm}^{2} / \mathrm{g}$, respectively. The density, Blaine fineness and $\mathrm{SiO}_{2}$ ratio of the silica fume used were $2210 \mathrm{~kg} / \mathrm{m}^{3}, 18000 \mathrm{~cm}^{2} / \mathrm{g}$ and $94.3 \%$, respectively. The aggregates used were quartz sand $\left(\mathrm{d}_{\max }=2.4 \mathrm{~mm}\right)$ and basalt $\left(\mathrm{d}_{\max }=9.5 \mathrm{~mm}\right)$. A styrene-butadiene rubber latex $(\mathrm{SBR})$ with an antifoamer agent was used as a cement modifier. The density and total solids of SBR used were $1020 \mathrm{~kg} / \mathrm{m}^{3}$ and $50.0 \%$, respectively. The density and total solids of the accelerating superplasticizer (SPA), sulfonated melamine formaldehyde were $1.11 \mathrm{~g} / \mathrm{cm}^{3}$ and $16.5 \%$, respectively.

Six concrete mixes with 1:1 ratio cement to aggregate were prepared at a W/A ratio of 0.40 (Table 1). The aggregate fraction for concretes was composed of $30 \%$ of sand and $70 \%$ of basalt aggregate, per weight. The silica fume dosage was $10 \%$ (S/C) of the cement weight. Superplasticiser at a dosage of $1.5 \%$ per weight of cement was added to the concrete with silica fume. The polymer/cement ratio (P/C, as solid polymer content per mass of cement) of SBR-modified concretes was 5 and $10 \%$. 
Table 1. Dosage of concretes.

\begin{tabular}{lccc}
\hline Type & $\begin{array}{c}\text { S/C }(\%) \\
\text { (per weight) }\end{array}$ & $\begin{array}{c}\text { P/C }(\%) \\
\text { (per weight) }\end{array}$ & $\begin{array}{c}\text { SPA/C }(\%) \\
\text { (per weight) }\end{array}$ \\
\hline 1 Ref. & - & - & - \\
2 & 10 & - & 1.5 \\
3 & - & 5 & - \\
4 & - & 10 & - \\
5 & 10 & 5 & 1.5 \\
6 & 10 & 10 & 1.5 \\
\hline
\end{tabular}

The microstructure of the ITZ was examined with a JSM-6400 scanning electronic microscope (SEM) connected to an energy Dispersion x ray Analyzer (EDX). The test samples of $20 \times 20 \times 5 \mathrm{~mm}$ were cut from 35 (diameter) $\times 70 \mathrm{~mm}$ cylinders in such a way that the investigated surface was parallel to the top surface of the cylinders. Tests were performed in 100-day-old specimens. Hydration was interrupted by alcohol. The specimens were impregnated under vacuum with a low-viscosity epoxy resin very carefully ground and polished with diamond paste.

Backscattered electron images of polished sections were obtained and quantitative $\mathrm{x}$ ray analyses were performed in ITZ perpendicular lines. Each line consisted of 15 points, 4 in the aggregates and 11 in the paste, with a distance between the points of above $7 \mu \mathrm{m}$. In each point quantitative analyses for $\mathrm{Na}, \mathrm{Mg}, \mathrm{Al}, \mathrm{Fe}, \mathrm{S}, \mathrm{Ca}, \mathrm{Si}, \mathrm{Mn}$ and $\mathrm{K}$ (oxygen was calculated stochiometrically) were made. For each type of concrete, 10 lines perpendicular to the ITZ were performed (Figure 1). Three polished specimens were used for each type of concrete. Only aggregates with $9.5 \mathrm{~mm}$ of diameter were considered. Each line was performed at different and arbitrarily chosen points of the specimens. In total, 900 analyses were conducted.

The analyses of compositions of major cement hydrated products (C-S-H, CH, AFm and Aft) were used to determine the ITZ thickness of the concretes. Based on researches by Kjellsen et al. ${ }^{15}$ and Taylor and Newburry ${ }^{16}$, the following compositions were assigned to the major hydrated phases:

$$
\begin{array}{lrll}
\text { C-S-H: } & 0.8 \leq \mathrm{Ca} / \mathrm{Si} \leq 2.5 & (\mathrm{Al}+\mathrm{Fe}) / \mathrm{Ca} \leq 0.2 & \\
\text { CH: } & \mathrm{Ca} / \mathrm{Si} \geq 10 & (\mathrm{Al}+\mathrm{Fe}) / \mathrm{Ca} \leq 0.04 & \mathrm{~S} / \mathrm{Ca} \leq 0.04 \\
\text { AFm: } & \mathrm{Ca} / \mathrm{Si} \geq 4.0 & (\mathrm{Al}+\mathrm{Fe}) / \mathrm{Ca}>0.4 & \mathrm{~S} / \mathrm{Ca}>0.15
\end{array}
$$

\section{Results and Discussions}

Figures 2 to 7 present the results of the semi-quantitative analysis by EDX associated with SEM, for the six types of concretes.

The values obtained for the relations $(\mathrm{Al}+\mathrm{Fe}) / \mathrm{Ca}$ and S/Ca indicate that none of the concretes studied showed substantial proportion either of $\mathrm{AFm}$ or $\mathrm{AFt}$, assuming that the $\mathrm{Al}, \mathrm{Fe}$ and $\mathrm{S}$ elements are present in the cement matrix, predominantly in the AFt and AFm phases. It can also be observed that there was no preferential region for the formation of AFm and AFt, as, for example, in the matrix-aggregate ITZ. Therefore, the ITZ thickness was determined through the analysis of the behavior of the $\mathrm{Ca} / \mathrm{Si}$ relation, which presented significant variation in the region next to the aggregate, thus allowing the identification of the ITZ.

The thickness of ITZ was defined as the distance between the matrix-aggregate interface and the point at which the values of the $\mathrm{Ca} / \mathrm{Si}$ relation presented stabilization. The thicknesses values of the ITZ, for the analyzed concretes, are shown in Figure 8.

The ITZ thickness obtained for the reference concrete, i.e., approximately $55 \mu \mathrm{m}$, is very close to the values obtained in several research-

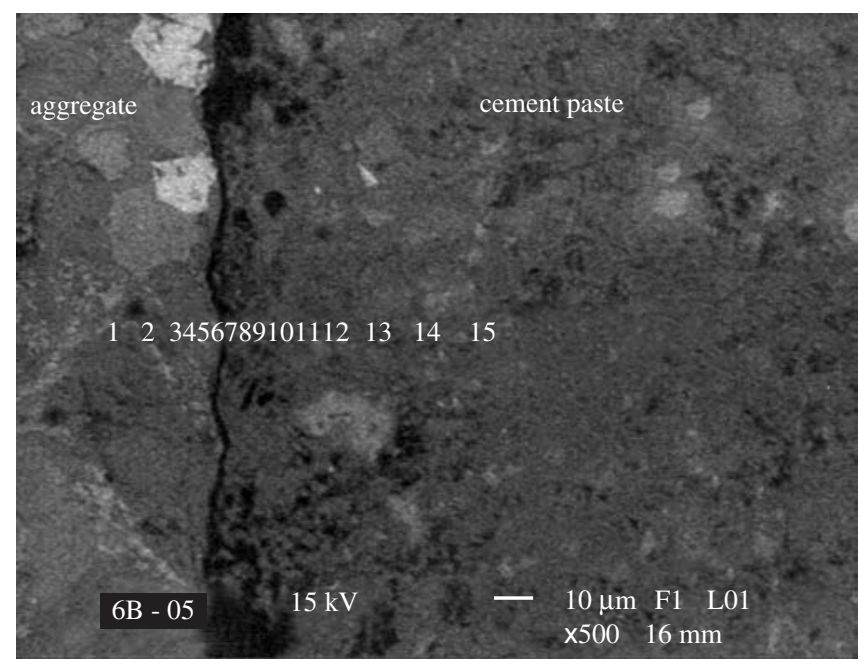

Figure 1. SEM-BSE images of ITZ perpendicular lines.

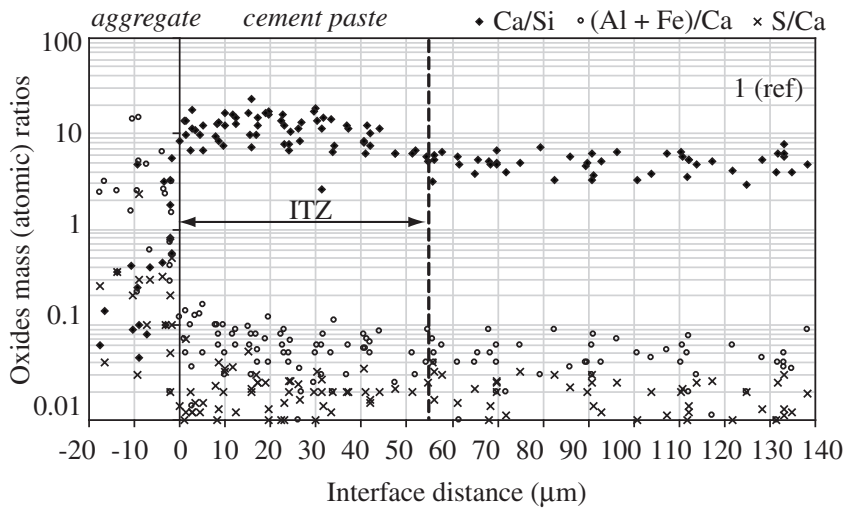

Figure 2. The ratios of $\mathrm{Ca} / \mathrm{Si},(\mathrm{Al}+\mathrm{Fe}) / \mathrm{Ca}$ and $\mathrm{S} / \mathrm{Ca}$ to concrete 1 (ref.).

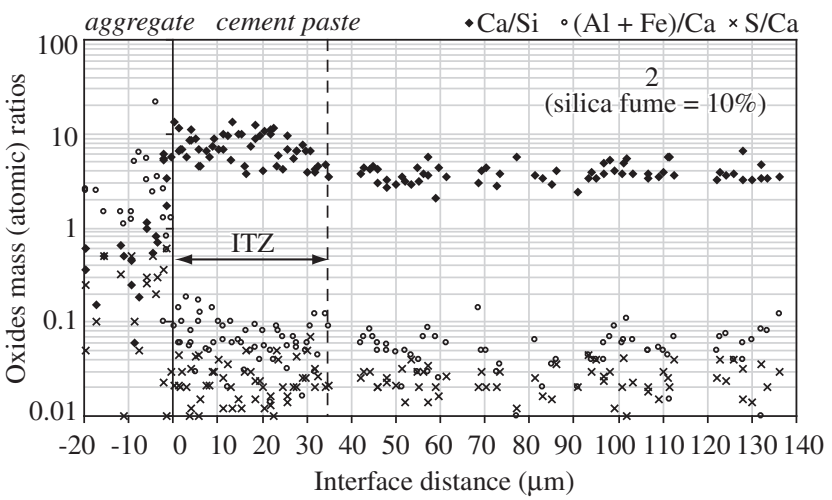

Figure 3. The ratios of $\mathrm{Ca} / \mathrm{Si},(\mathrm{Al}+\mathrm{Fe}) / \mathrm{Ca}$ and $\mathrm{S} / \mathrm{Ca}$ to concrete 3 $(\mathrm{S} / \mathrm{C}=10 \%)$.

es $\mathrm{s}^{6,11,15}$ for concretes without additions or addictives. Although the most usual values for the thickness of the ITZ are between 40 and $60 \mu \mathrm{m}$ in the concrete without additions or addictives, they can vary significantly, due to the type of cement and the water/binder relation used.

The results presented demonstrated that the utilization of either silica fume or SBR latex causes a significant reduction in the matrix- 


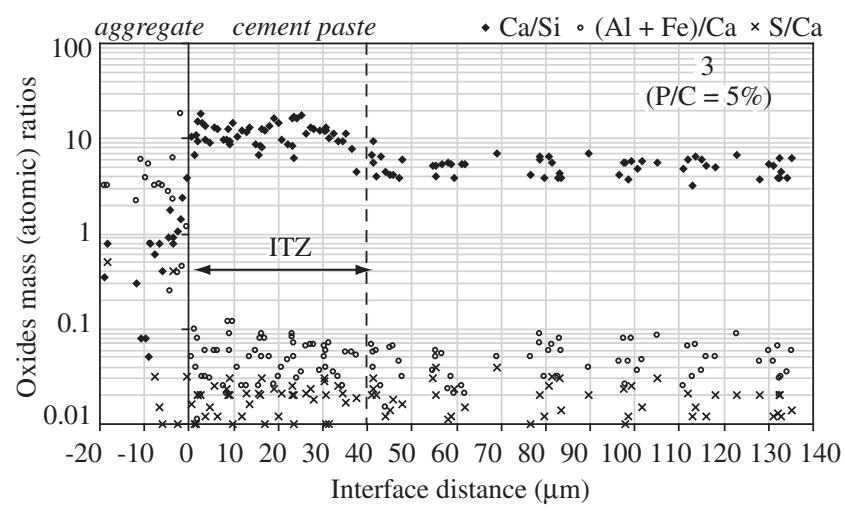

Figure 4. The ratios of $\mathrm{Ca} / \mathrm{Si},(\mathrm{Al}+\mathrm{Fe}) / \mathrm{Ca}$ and $\mathrm{S} / \mathrm{Ca}$ to concrete $3(\mathrm{P} / \mathrm{C}=$ $5 \%$ ).

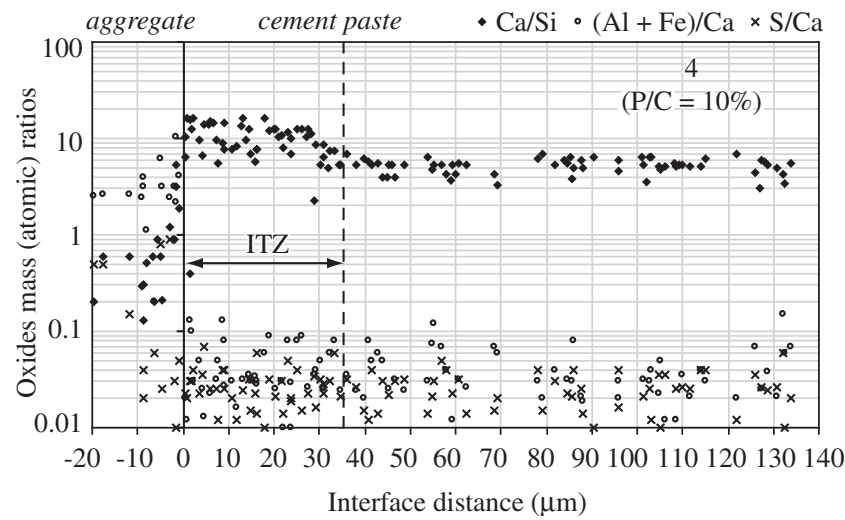

Figure 5. The ratios of $\mathrm{Ca} / \mathrm{Si},(\mathrm{Al}+\mathrm{Fe}) / \mathrm{Ca}$ and $\mathrm{S} / \mathrm{Ca}$ to concrete 4 $(\mathrm{P} / \mathrm{C}=10 \%)$.

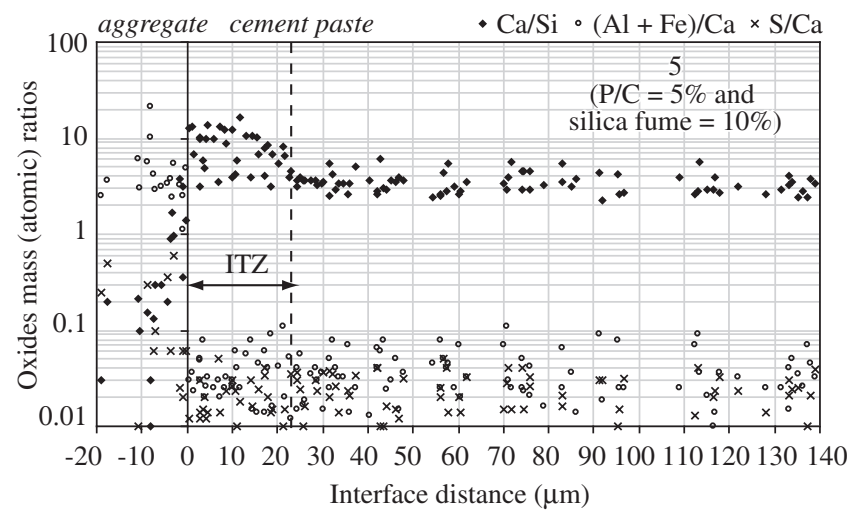

Figure 6. The ratios of $\mathrm{Ca} / \mathrm{Si},(\mathrm{Al}+\mathrm{Fe}) / \mathrm{Ca}$ and $\mathrm{S} / \mathrm{Ca}$ to concrete $5(\mathrm{P} / \mathrm{C}=5 \%$ and $\mathrm{S} / \mathrm{C}=10 \%$ ).

aggregated ITZ thickness, besides decreasing the $\mathrm{CH}$ proportion in that region, in comparison to the reference concrete, which can be verified in the reduction of the values of the $\mathrm{Ca} / \mathrm{Si}$ relation in the ITZ (Figures 3 to 5).

The $36 \%$ thickness reduction in the ITZ with the utilization of $10 \%$ of silica fume can be explained by the following: i) less permeability of the fresh concrete, thus causing less water accumulation in

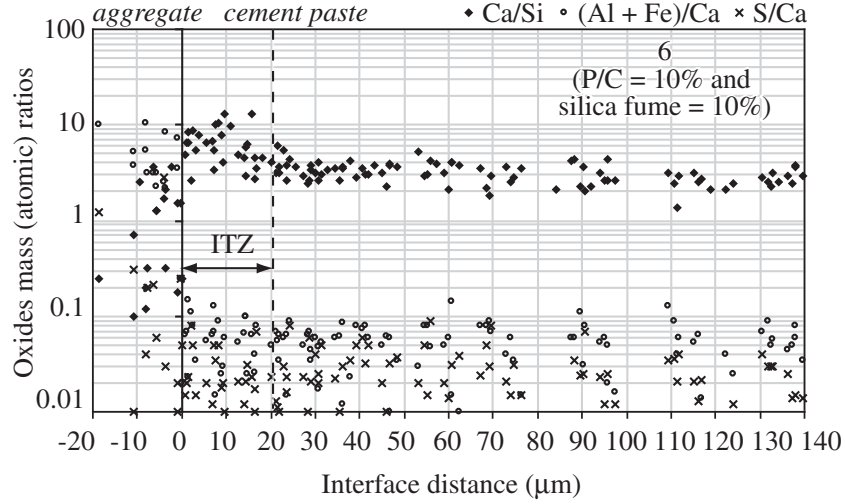

Figure 7. The ratios of $\mathrm{Ca} / \mathrm{Si},(\mathrm{Al}+\mathrm{Fe}) / \mathrm{Ca}$ and $\mathrm{S} / \mathrm{Ca}$ to concrete $5(\mathrm{P} / \mathrm{C}=10 \%$ and $\mathrm{S} / \mathrm{C}=10 \%$ ).

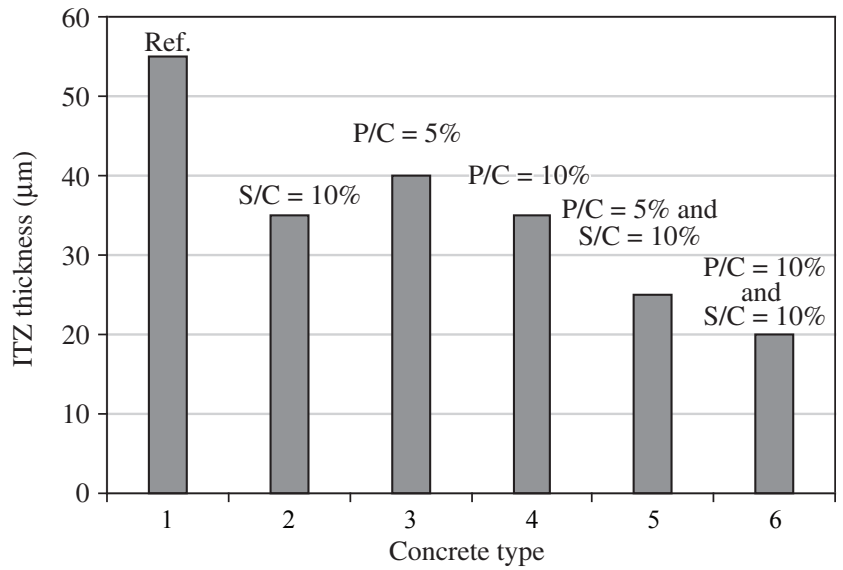

Figure 8. Interfacial transition zone thickness of the concretes.

the aggregated surface; ii) the presence of several crystallization nuclei, which contributes to the formation of smaller calcium hydroxide crystals with less crystallization tendency in preferential orientations; iii) and the gradual densification of the hydration products systems by means of pozolanic actions between the calcium hydroxide and the silica fume ${ }^{17}$.

In the concrete modified with SBR latex, the reduction values of the matrix-aggregate ITZ thickness were $27 \%(\mathrm{P} / \mathrm{C}=5 \%)$ and $36 \%$ $(\mathrm{P} / \mathrm{C}=10 \%)$. This effect can be explained, according to the results of some recent researches ${ }^{12-14}$, by two factors: the chemical interaction between the polymer particles and some products of the cement hydration, specially $\mathrm{Ca}^{2+}$, which alters the quantity and composition of some products of the cement hydration, specially calcium hydroxide $(\mathrm{CH})$; and the porosity reduction in the cement matrix in the region next to the aggregate, as this area generally presents a higher water quantity than the cement matrix, as a result of the wall effect and consequently higher polymer quantity, since in the modified concretes the polymer is homogeneously disperse in the aqueous element.

In the concretes containing silica fume and SBR latex, the highest values of the reduction of the ITZ thickness were observed - 54\% $(\mathrm{P} / \mathrm{C}=5 \%$ and $\mathrm{S} / \mathrm{C}=10 \%)$ and $64 \%(\mathrm{P} / \mathrm{C}=10 \%$ and $\mathrm{S} / \mathrm{C}=10 \%)$ with the smallest $\mathrm{CH}$ proportion in that area, analyzing comparatively the values of the $\mathrm{Ca} / \mathrm{Si}$ relation (Figures 6 and 7). Such effect demonstrates a synergism of those products for the improvement of the cement quality matrix in the ITZ. 


\section{Conclusions}

In the results obtained from the microstructural analyses of the concretes, it was observed that the usage of $10 \%$ of silica fume, in relation to the cement paste, caused a reduction of $36 \%$ in the thickness of the matrix-aggregate ITZ, in relation to the reference concrete.

In the concretes modified with SBR latex, the values of the thickness reduction of the matrix-aggregate ITZ were $27 \%(\mathrm{P} / \mathrm{C}=5 \%)$ and $36 \%(\mathrm{P} / \mathrm{C}=10 \%)$, when compared with the reference concrete.

The highest values of the thickness reduction of the ITZ were obtained for the concretes which used both silica fume and SBR latex. The reduction was of $54 \%$ for concretes with $\mathrm{P} / \mathrm{C}=5 \%$ and $\mathrm{S} / \mathrm{C}=10 \%$ and $64 \%$ for concretes with $\mathrm{P} / \mathrm{C}=10 \%$ and $\mathrm{S} / \mathrm{C}=10 \%$, in relation to the reference concrete.

It was also observed that, in the concretes with either silica fume or SBR latex, besides the thickness reduction of the ITZ, there was a quality improvement in the hydration products of Portland cement in that area, as a consequence of the decrease in the $\mathrm{CH}$ proportion. That effect was more relevant in concretes combining both silica fume and SBR latex.

\section{Acknowledgments}

The author is indebted to the Research Sponsoring Foundation of São Paulo State (Fundação de Apoio à Pesquisa do Estado de São Paulo - FAPESP) for the financial support given to this research, as well as the Civil Engineering National Laboratory (Laboratório Nacional de Engenharia Civil - LNEC) in Lisbon, Portugal, for having accomplished the experimental analyses.

\section{References}

1. Rossignolo JA, Agnesini MVC, Morais JA. High-Performance LWAC for Precast Structures: Properties in the Fresh and Hardened State. Proceedings of the Second International Symposium on Structural Lightweight Aggregate Concrete, 2000; Kristiansand, NORUEGA. p. 699-708.

2. Rossignolo JA, Agnesini MVC. Polymer modified lightweight aggregate concrete: Properties in fresh state, strength and water absorption. Proceedings of the 10th International Congress on Polymers in Concrete. 2001; Honolulu, HAWAI. p. 01-06.

3. Rossignolo JA, Agnesini MVC. Mechanical properties of polymer modified lightweight aggregate concrete. Cement and Concrete Research. 2002; 32(3):329-334.
4. Rossignolo JA, Agnesini MVC, Morais JA. Properties of High-Performance LWAC for Precast Structures with Brazilian Lightweight Aggregates. Cement and Concrete Composites. 2003; 25(1):77-82.

5. Rossignolo JA, Agnesini MVC. Durability of polymer-modified lightweight aggregate concrete. Cement and Concrete Composites. 2004; 26(4):375-380.

6. Monteiro PJM. Microstructure of concrete and its influence on the mechanical properties. [ $\mathrm{PhD}$ dissertation]. Berkeley: University of California; 1985.

7. Maso JC. Influence of the interfacial transition zone on composite mechanical properties. In: Maso JC, editor. Interfacial Transition Zone in Concrete. London, E \& FN SPON, 1996, p. 103-16.

8. Kobayashi K, Hattori A, Miyagawa T. Characters of interfacial transition zone cement with admixtures. In: Katz A, et al. The Interfacial Transition Zone in Cementitius Composites. London, E \& FN SPON, 1998, p. 311-17.

9. Kjellsen KO, Wallevik OH, Fjällberg L. Microstructures and microchemistry of the paste-aggregate interfacial transition zone of high-performance concrete. Advances in Cement Research. 1998; 10(1):33-40.

10. Monteiro PJM, Metha PK. Interaction between carbonate rock and cement paste. Cement and Concrete Research.1986; 16(1):127-32.

11. Monteiro PJM, Metha PK. Effect of aggregate, cement, and mineral admixtures on the microstructure of the transition zone. Invited Paper, MRS Society, Boston; 1988

12. Sakai E, Sugita J. Composite mechanism of polymer modified cement. Cement and Concrete Research. 1995. 25(1):127-35.

13. Ollitrauly-Fichet R. et al. Microstructural aspects in a polymer-modified cement. Cement and Concrete Research. 1998; 28(12):1687-1693.

14. Beeldens A. et al. Influence of polymer type on the structure of polymer modified cement mortar. In: Proceedings of the $21^{\text {th }}$ International Conference on Cement Microscopy, 1999. Las Vegas, USA. p. 59-71.

15. Kjellsen KO, Wallevik OH, Fjällberg L. Microstructures and microchemistry of the paste-aggregate interfacial transition zone of high-performance concrete. Advances in Cement Research. 1998; 10(1):33-40.

16. Wasserman R, Bentur A. Interfacial interactions in lightweight aggregate concretes and their influence on the concrete strength. Cement and Concrete Composites. 1996; 18(1):67-76.

17. Bentur A, Cohen MD. Effect of condensed silica fume on the microstructure of the interfacial zone in Portland cement mortars. Journal of the American Ceramic Society. 1987; 70(10):738-743. 